\title{
Real-Time Analysis and Forecasting of Multisite River Flow Using a Distributed Hydrological Model
}

\author{
Mingdong Sun and Gwangseob Kim \\ Department of Civil Engineering, Kyungpook National University, Daegu 702701, Republic of Korea \\ Correspondence should be addressed to Mingdong Sun; sunmingdong@hotmail.com
}

Received 8 July 2014; Accepted 18 August 2014; Published 18 December 2014

Academic Editor: Yoshinori Hayafuji

Copyright ( 2014 M. Sun and G. Kim. This is an open access article distributed under the Creative Commons Attribution License, which permits unrestricted use, distribution, and reproduction in any medium, provided the original work is properly cited.

\begin{abstract}
A spatial distributed hydrological forecasting system was developed to promote the analysis of river flow dynamic state in a large basin. The research presented the real-time analysis and forecasting of multisite river flow in the Nakdong River Basin using a distributed hydrological model with radar rainfall forecast data. A real-time calibration algorithm of hydrological distributed model was proposed to investigate the particular relationship between the water storage and basin discharge. Demonstrate the approach of simulating multisite river flow using a distributed hydrological model couple with real-time calibration and forecasting of multisite river flow with radar rainfall forecasts data. The hydrographs and results exhibit that calibrated flow simulations are very approximate to the flow observation at all sites and the accuracy of forecasting flow is gradually decreased with lead times extending from $1 \mathrm{hr}$ to $3 \mathrm{hrs}$. The flow forecasts are lower than the flow observation which is likely caused by the low estimation of radar rainfall forecasts. The research has well demonstrated that the distributed hydrological model is readily applicable for multisite real-time river flow analysis and forecasting in a large basin.
\end{abstract}

\section{Introduction}

River and coastal flooding are principal problems in water resource management throughout the world. Many kinds of flooding models and model applications were presented in the field of river flow research. In order to achieve the estimation of river flow, a series of related models is required including appropriate types of stream flow models and essential hydrological data. The models are simplified conceptual depiction of the actual existence of hydrological processes in the catchment area. Hapuarachchi et al. [1] reviewed some recently emerging advanced researches on the application of new modeling technology and data processing approaches in flash flood forecasting in the past decade.

The principal advantages of the distributed flood models are as follows: they have physically based characteristic hydrological modeling approach that requires the elaborate spatial physical variations and parameters; they guarantee that all relevant processes are recurred exactly; they make appropriate response to a varying climate of study basin compared to empirical or conceptual models. These profits are more especially suitable for simulating large basin with the mutative heavy precipitation spread-over. Coupling with GIS system that considers spatial variability of the available information, it can provide the physical basis for establishing the necessary model parameters in a distributed model.

As the physically based characteristic, distributed flood models have represented outstanding attraction and become a more feasible approach in analysis of flooding flow on large basin. And available high spatial resolution data also led to a full development of many advanced distributed hydrological models. Kuchment [2] presented a distributed rainfall-runoff model using the two-dimensional kinematic wave method for overland flow routing and Chezy roughness coefficient to describe surface roughness. Schultz et al. [3] showed an earlier study using a distributed system approach and an optimal technology to calibrate model parameters for simulating runoff of a given watershed using radar rainfall measurements. Vieux and Jones [4] exhibited a distributed watershed model which incorporated with Geographic Resources Analysis Support System (GRASS) GIS system and applied a finite element approach for flood forecasting with hourly WSR-88D radar data. 


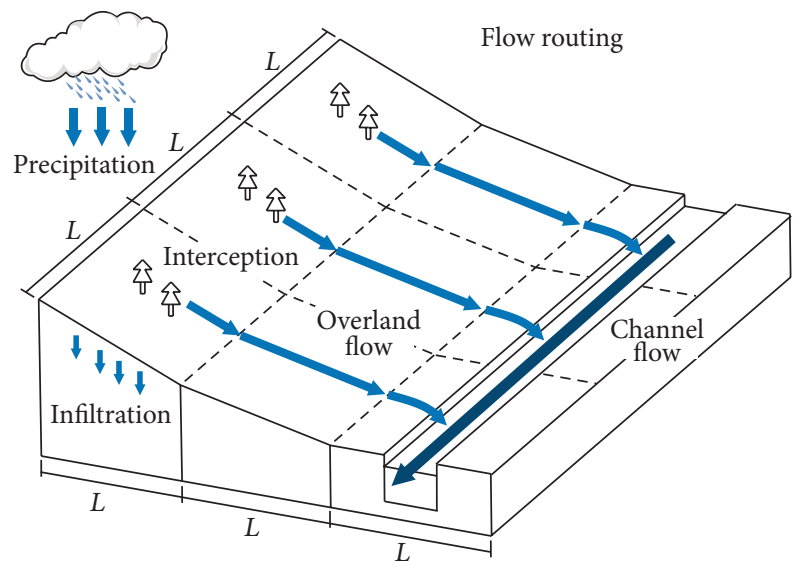

FIGURE 1: Framework for distributed hydrological model.

For large basin, while constructing design and real-time operational river flow analysis may be required to estimate the flow at some interior locations in a river basin, accurate forecasting in a real-time rainfall-runoff simulation can be got from set fundamental model parameters effectively and give properly assessed initial state variables and input data. Flow simulation accuracy could be improved when the parameters or state variables are updated with real-time observation of stream flow.

The main objectives of this study are to demonstrate the approach of a distributed hydrological model couple with real-time calibration technology for multisite real-time river flow analysis and forecasting in a large basin with radar rainfall forecasts data. Comparisons of the hydrographs with different lead-time precipitation forecasts will be drawn to see how the precipitation forecasts influence the forecasting.

\section{Methodologies}

2.1. Model Description. A physically based, spatially distributed explicit hydrological model [5] is used for simulating the hydrological process of a watershed dependent on an input rainfall field. It is highly significant to conceptualize the given watershed to the two-dimensional spatial resolution for leading calculation. The square grid structure is defined on the watershed and the numerical solution for the calculation of continuity and momentum equations are evaluated for each grid cell within the watershed. Major components of the model include precipitation distributed input, interception, infiltration, surface overland flow, and channel runoff routing. The major components of the distributed hydrological model are detailedly shown in Figure 1.

2.1.1. Precipitation. Precipitation input data from measurements at multiple gauge networks or weather radar estimation: for rain gauge data, the spatial distribution of precipitation over every grid cell is computed using inverse distance weighting technique [6] or the Thiessen polygons method [7].

2.1.2. Interception. Interception process is modeled empirically depending on the vegetation coverage [8]. Rather than eventually reaching the ground, interception of rainfall refers

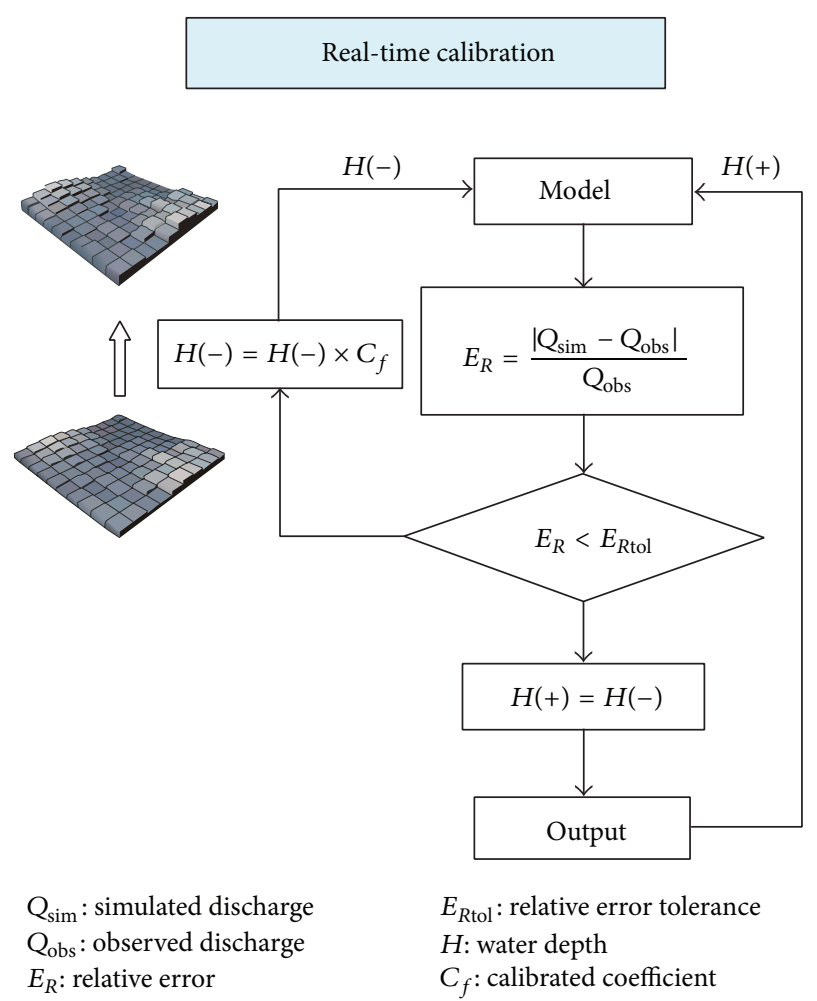

FIgURE 2: Real-time calibration process.

to the part of precipitation that does not fall to the earth but is intercepted by the leaves, branches of plants, and the forest floor and then evaporates directly and does not take part in ultimate runoff; thus it is usually termed interception loss [9]. Measured values of interception capacity depth for a series of various vegetative canopies are found in Woolhiser et al. [10] and Bras [11].

2.1.3. Infiltration. Infiltration rate is a measure capable of soil absorption of rainfall water in hydrology science. In the model, a method developed by Green and Ampt [12] closely calculated infiltration rate and cumulative infiltration depth for each grid element in the study watershed:

$$
f(t)=K\left[\frac{\psi \Delta \theta}{F(t)}+1\right],
$$

where $f$ : infiltration rate; $\psi$ : wetting front soil suction head; $\theta$ : water content; $K$ : hydraulic conductivity; $F$ : cumulative infiltration volume.

Applying the Green-Ampt method demands many variables and requires estimations of soil characteristics such as hydraulic conductivity, effective porosity, capillary suction head, and initial soil moisture deficit for each grid cell. The numerical parameters values can be acquired from the experimental data depending on the soil texture by Rawls et al. [13].

2.1.4. Overland Flow. Routing of the overland flow is in a way of two-dimensional cascading from every one cell to the other downstream cell. The governing equations for overland flow in the model are primarily based on the de Saint-Venant 


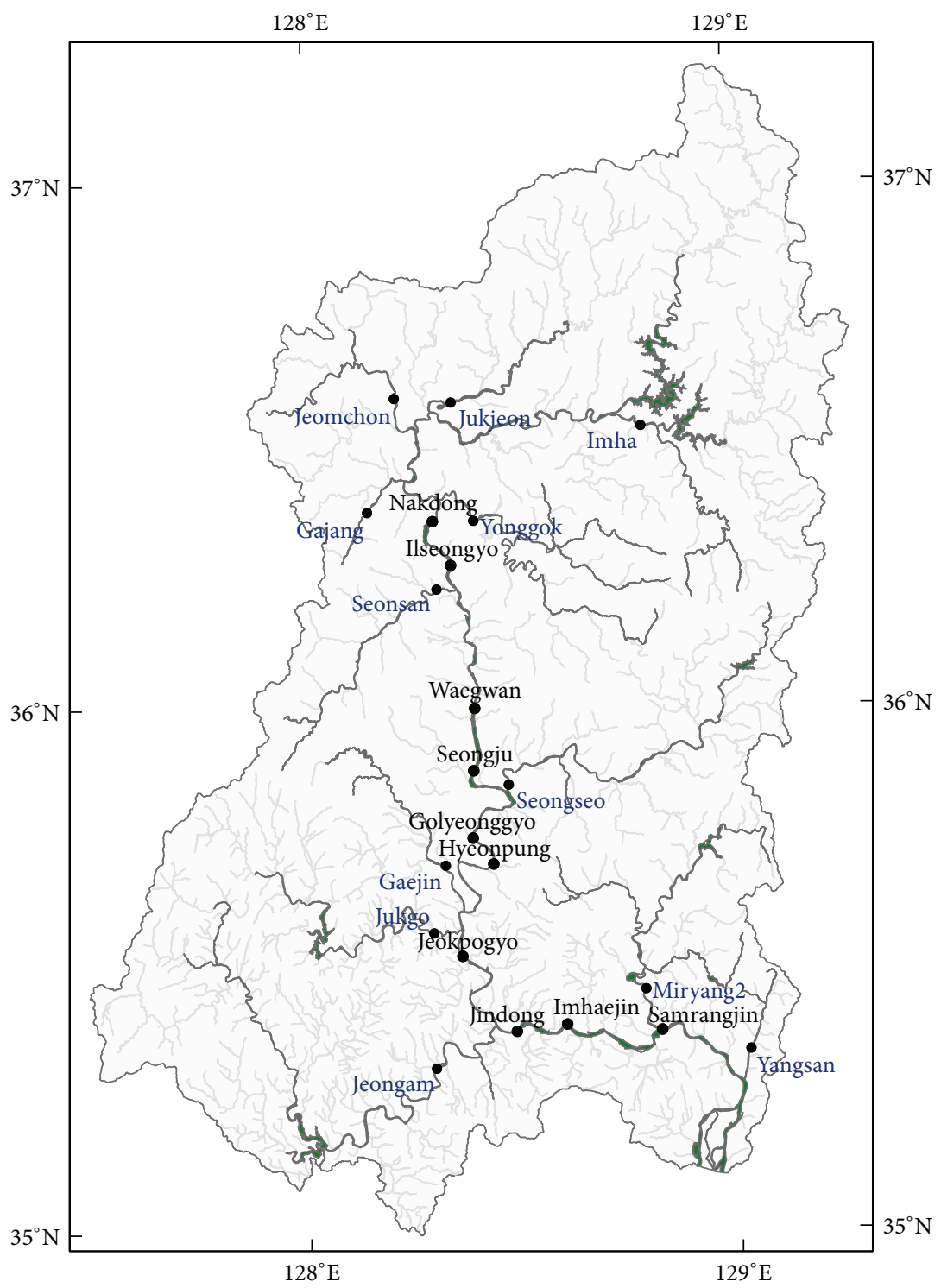

Figure 3: The Nakdong River Basin and 22 observation sites locations.

equations of continuity and momentum. From the equations of continuity and momentum, a relationship that relates the flow rate to depth can be established as

$$
q=\frac{S_{f}^{1 / 2}}{n} h^{5 / 3},
$$

where $h$ : surface water depth; $q$ : unit flow rate in the $x$ direction and $y$ direction; $S_{f}$ : friction slopes in the flow direction; $n$ : Manning roughness coefficient.

The coefficient $n$ can be estimated from the land use map using the assigned values [14].

2.1.5. Channel Flow. The process of conveying flow water through a defined channel network is based on the onedimensional diffusive wave channel flow scheme [15]. The governing equations for the channel flow routing process are mathematically similar to the calculations of overland flow.
The formula in the model to compute the channel discharge rate can be expressed by the following equation:

$$
Q=\frac{1}{n} A R^{2 / 3} S_{f}^{1 / 2},
$$

where $Q$ : discharge flow rate; $n$ : Manning roughness coefficient; $A$ : cross-sectional area of flow; $R$ : hydraulic radius; $S_{f}$ : friction slope.

2.2. Calibration Algorithm. The model simulation calibration is a necessary process to improve the model performance. The river flow simulation accuracy can be improved when the state variables are calibrated with real-time observation of stream flow. When the water depth of channel flow is considered as a state variable, an observation equation which specifies a relationship between observed data of defined sites and water depth values is derived easily. According to (3), 

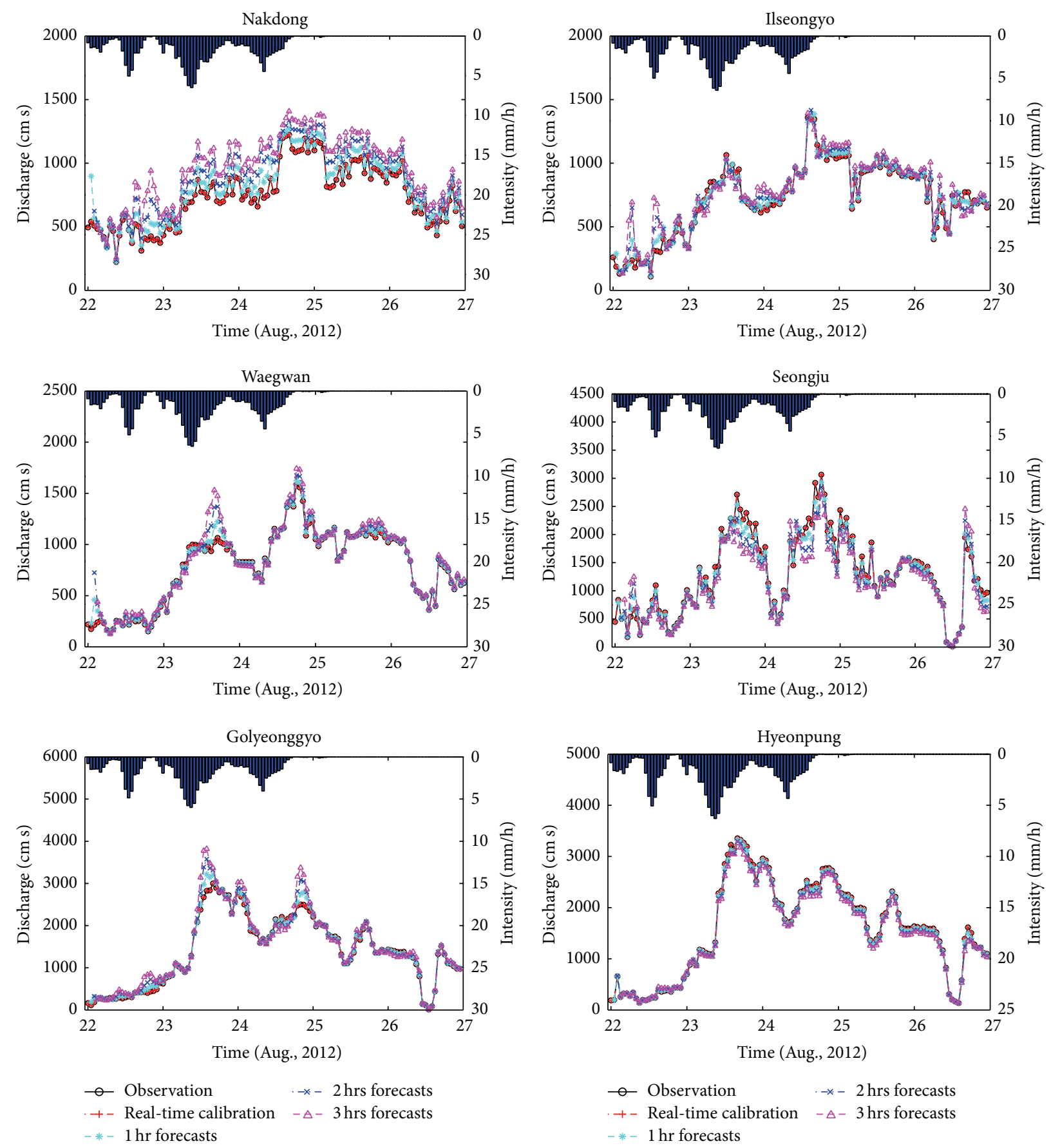

Figure 4: Performance of real-time calibrated simulation and flow forecasting results of sites Nakdong, Ilseongyo, Waegwan, Seongju, Golyeonggyo, and Hyeonpung located at Nakdong River.

specified stage-discharge relationship corresponding to the water depths can be expressed as

$$
\begin{aligned}
Q & =\frac{1}{n} A R^{2 / 3} S_{f}^{1 / 2}=\frac{1}{n} W h\left(\frac{W h}{W+2 h}\right)^{2 / 3} S_{f}^{1 / 2} \\
& =\frac{1}{n} \frac{(W h)^{5 / 3}}{(W+2 h)^{2 / 3}} S_{f}^{1 / 2},
\end{aligned}
$$

where $h$ : water depth of channel flow; $W$ : width of channel.
According to (4), the relation between discharge $Q$ and water depth $h$ is formulated.

In order to calibrate the water depth through the calibration algorithm, the calibrating measure should be distributed to each cell in the objective region. One efficient way to update the water depth of each cell in the region is using a specific ratio calculated from the updated stage-discharge relationship. Based on (4), the calibrated coefficient can be accurately estimated by Newton-Raphson method. As shown 

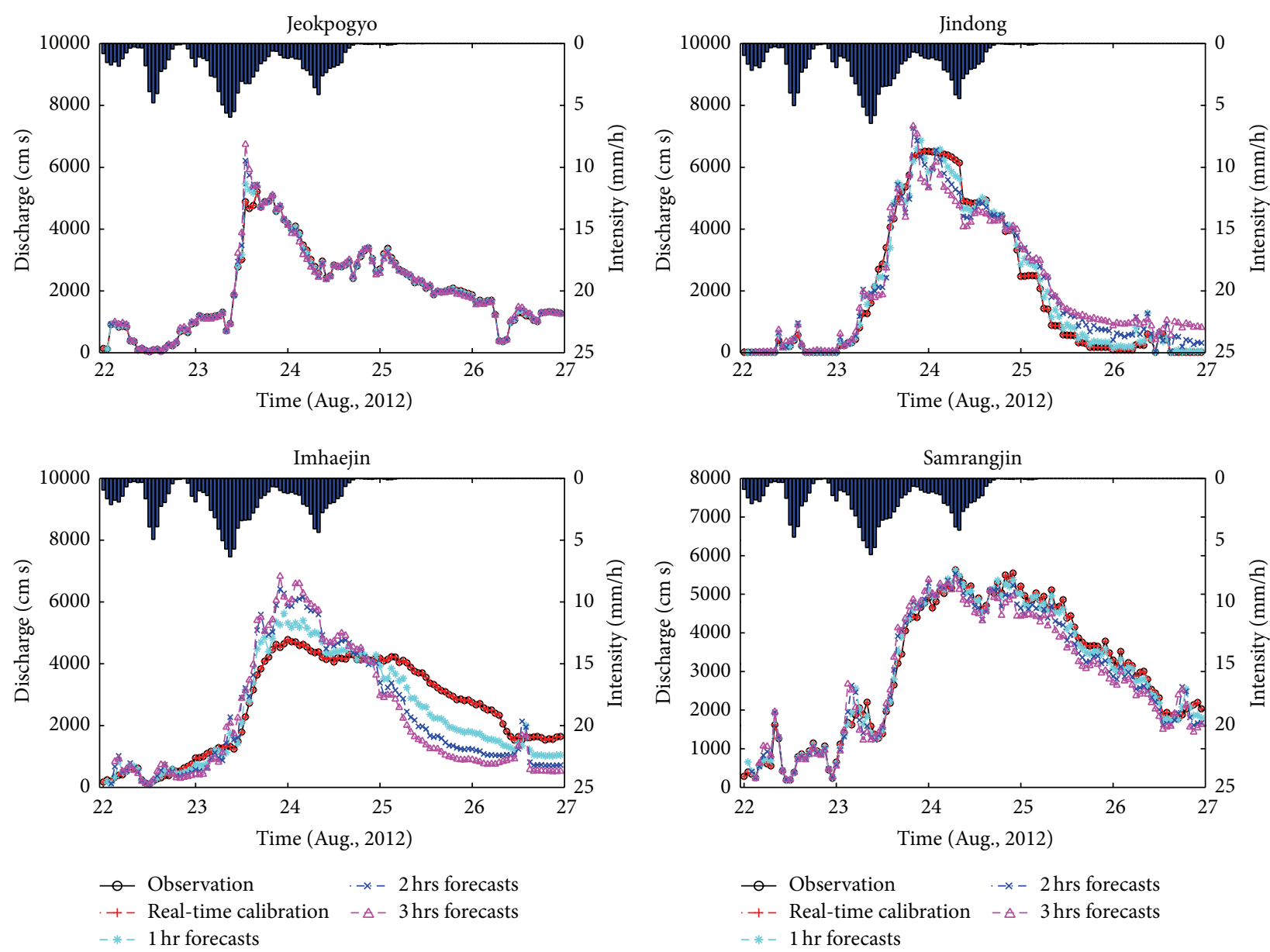

FIGURE 5: Performance of real-time calibrated simulation and flow forecasting results of sites Jeokpogyo, Jindong, Imhaejin, and Samrangjin located at Nakdong River.

in Figure 2, the calculated coefficient is applied to the water depth of each cell during model operating; the simulated water depth of each cell at a specific time step is calibrated by a coefficient and then the simulation commences again with updated state variable of each cell. This method offers applicable and effective updating skill of state variables considering its spatial distribution pattern with the simulation result.

For the situation of multisite flow calibration in a large basin, several objective regions are plotted based on corresponding upper stream contributing area of the respective observation site which locates at the basin.

2.3. Measure Skills. Two numerical measure skills are employed for evaluating the goodness of model performance in this study: root mean square error (RMSE) and Nash-Sutcliffe model efficiency coefficient (EC) [16]. The Nash-Sutcliffe coefficient properly assesses the efficiency of hydrological models. The RMSE and EC are given by the following equations:

$$
\mathrm{RMSE}=\sqrt{\frac{\sum_{i=1}^{n}\left(Q_{m}^{i}-Q_{o}^{i}\right)^{2}}{n}},
$$

$$
\mathrm{EC}=1-\frac{\sum_{i=1}^{n}\left(Q_{o}^{i}-Q_{m}^{i}\right)^{2}}{\sum_{i=1}^{n}\left(Q_{o}^{i}-\bar{Q}_{o}\right)^{2}},
$$

where $Q_{m}$ : modeled simulation; $Q_{o}$ : observed flow; $\bar{Q}$ : mean of the observed flow; $n$ : number of $Q_{m}$ and $Q_{o}$ values.

Optimal values for RMSE and EC are 0 and 1, respectively.

\section{Data Description}

The Nakdong River Basin is located in the monsoon region of South Korea. The main channel of the Nakdong River is $526 \mathrm{~km}$ long, the catchment area approximately about $23,702 \mathrm{~km}^{2}$, about $24 \%$ of the entire land in South Korea. Figure 3 provides a location map for the Nakdong River Basin. The Nakdong River Basin includes numerous floodplain wetlands and is characterized by intense rainfall and several typhoon events in the monsoon season.

The data of Nakdong River Basin that were collected for distributed hydrological model included gauge and radar rainfall, digital elevation, land cover, soil type, channel network information, and stream flow data. The requisite data 

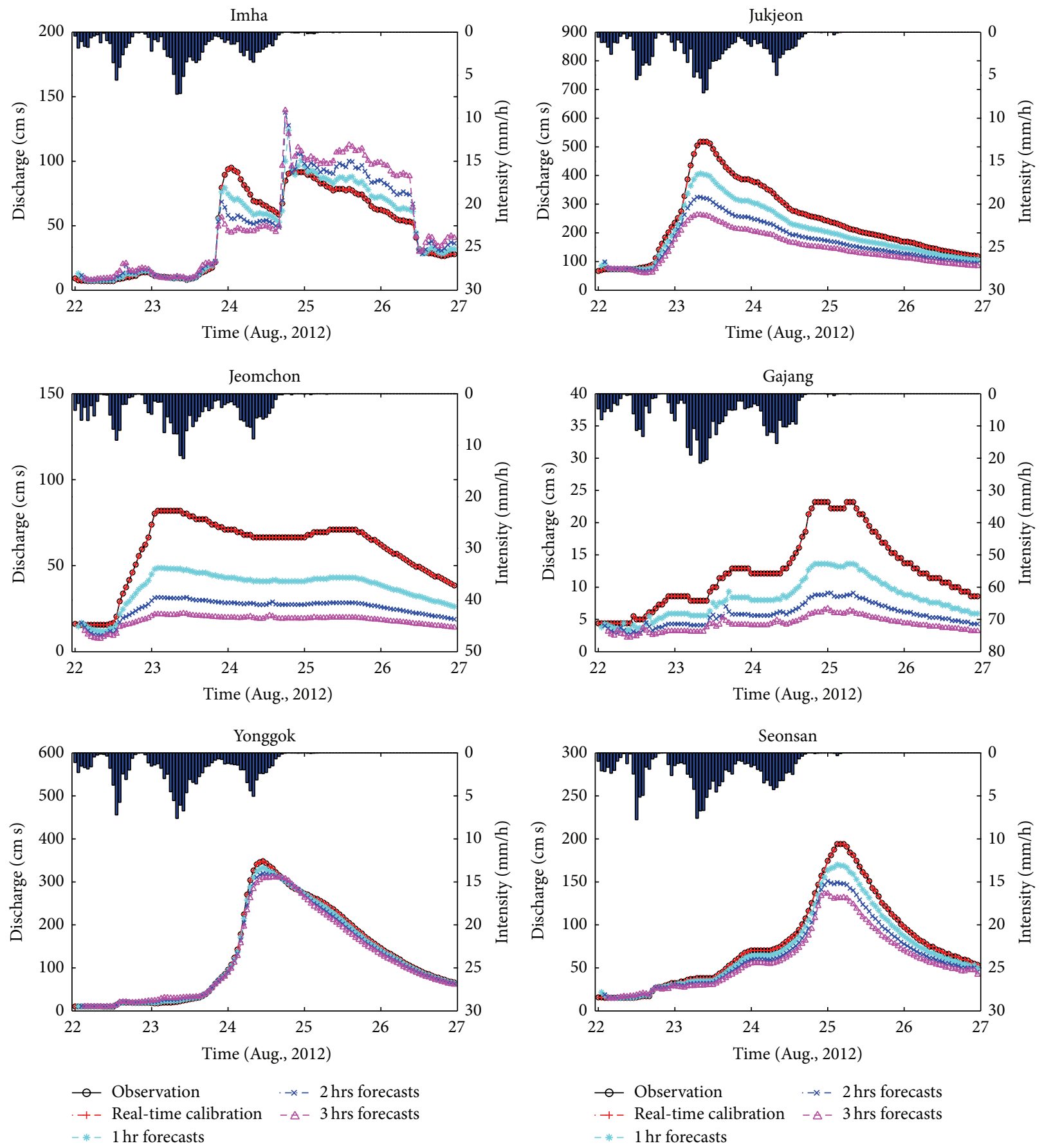

Figure 6: Performance of real-time calibrated simulation and flow forecasting results of sites Imha, Jukjeon, Jeomchon, Gajang, Yonggok, and Seonsan located at the tributaries of the Nakdong River.

and information for model were obtained mostly from the Water Management Information System (WAMIS) in South Korea. The grid data are provided in a raster format with spatial resolution and were resampled to a spatial resolution of $1 \mathrm{~km} \times 1 \mathrm{~km}$ using the ArcGIS system. The radar rainfall data were obtained from Biseulsan radar whose observation radius is $100 \mathrm{~km}$, and Nakdong River Basin is situated in the center of radar coverage. As showed in Figure 3, 22 observational sites are located through the stream of the Nakdong
River Basin, where 10 sites located at Nakdong River and 12 sites located at its tributaries.

\section{Results and Discussion}

The procedure that uses the distributed hydrological model to calibrate and forecast river flow of Nakdong River Basin is as follows: in real-time calibrate the flow simulation with flow observation using calibration algorithm; gauge rainfall data 

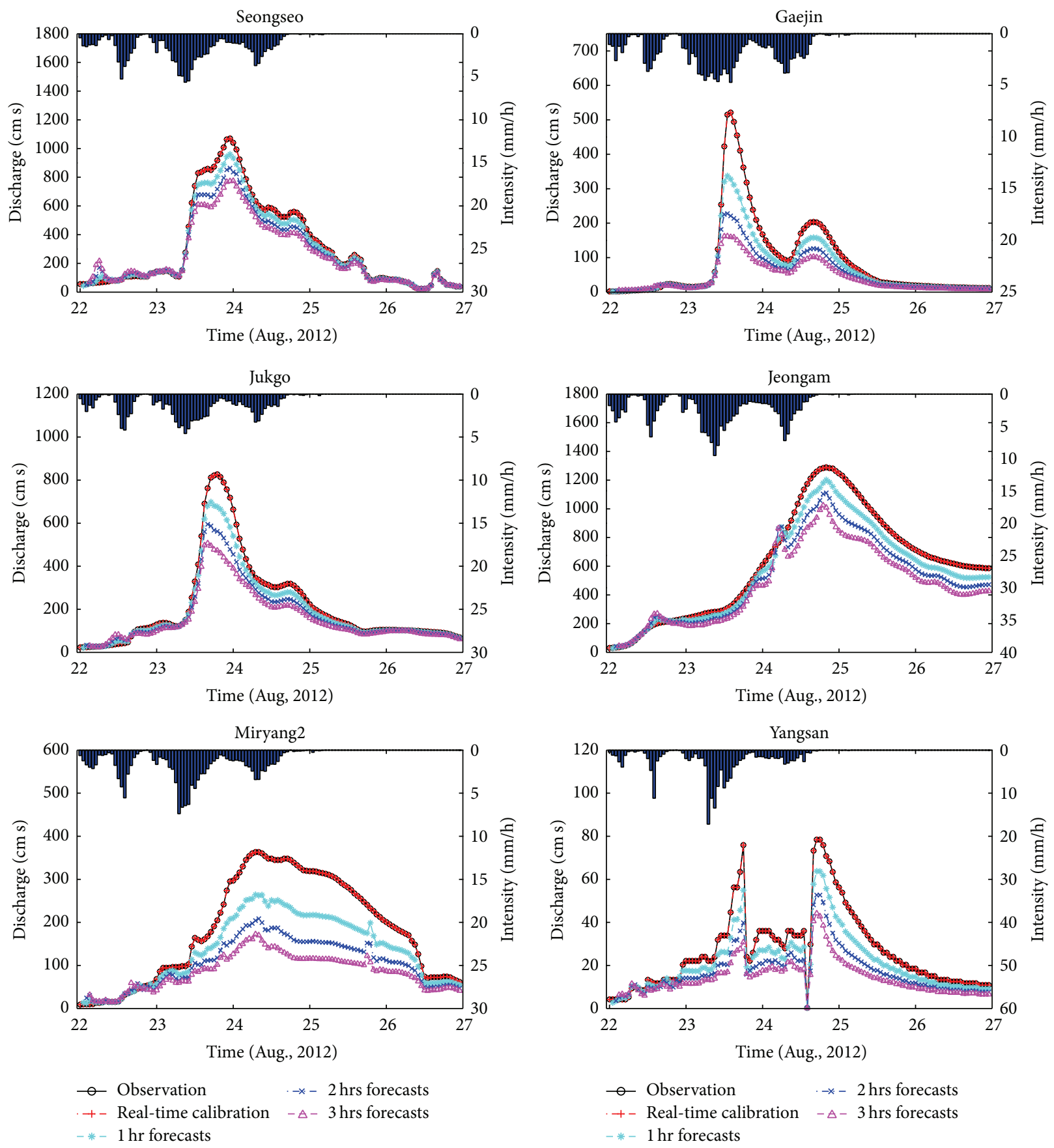

FIGURE 7: Performance of real-time calibrated simulation and flow forecasting results of sites Seongseo, Gaejin, Jukgo, Jeongam, Miryang2, and Yangsan located at the tributaries of the Nakdong River.

as the precipitation input and every observation is updated every hour; forecast the river flow of future $1 \mathrm{hr}, 2 \mathrm{hrs}$, and $3 \mathrm{hrs}$ using radar rainfall forecasts data as the precipitation input. The precipitation forecasts of $1 \mathrm{hr}, 2 \mathrm{hrs}$, and $3 \mathrm{hrs}$ were generated from the radar rainfall images and became rainfall input file for the model at each forecast time increment.

The model is applied to the Nakdong River Basin with the August 2012 event that started on August 22 and continued through the lasting 5 days. The approach is capable of realtime calibration and forecast of river flow involved extrapolation of flow patterns based on model. In this approach, hydrographs of 22 sites are generated to inspect the applicability and efficiency of model's simulation and forecasting. Figures 4 and 5 show the performance of real-time calibrated simulation and $1 \mathrm{hr}, 2 \mathrm{hrs}$, and $3 \mathrm{hrs}$ flow forecasting results whose site locates at Nakdong River; Figures 6 and 7 show the 
TABLE 1: RMSE and EC from the flow forecasting results of $1 \mathrm{hr}, 2 \mathrm{hrs,}$ and 3 hrs.

\begin{tabular}{lcccccc}
\hline \multirow{2}{*}{ Index } & \multicolumn{1}{c}{$1 \mathrm{hr}$ forecasts } & \multicolumn{2}{c}{ 2 hrs forecasts } & \multicolumn{2}{c}{$3 \mathrm{hrs}$ forecasts } \\
& RMSE & EC & RMSE & EC & RMSE & EC \\
\hline Nakdong & 78.77 & 0.87 & 148.80 & 0.56 & 221.78 & 0.09 \\
Ilseongyo & 39.33 & 0.98 & 76.84 & 0.92 & 105.12 & 0.86 \\
Waegwan & 40.39 & 0.99 & 82.00 & 0.94 & 101.58 & 0.87 \\
Seongju & 102.86 & 0.98 & 194.29 & 0.92 & 278.53 & 0.85 \\
Golyeonggyo & 82.42 & 0.99 & 166.97 & 0.96 & 247.04 & 0.91 \\
Hyeonpung & 40.01 & 0.99 & 77.32 & 0.98 & 109.80 & 0.97 \\
Jeokpogyo & 93.74 & 0.99 & 184.62 & 0.97 & 251.67 & 0.96 \\
Jindong & 267.08 & 0.99 & 503.95 & 0.95 & 675.59 & 0.92 \\
Imhaejin & 579.15 & 0.86 & 996.29 & 0.58 & 1222.31 & 0.37 \\
Samrangjin & 174.42 & 0.99 & 331.53 & 0.96 & 458.77 & 0.93 \\
Imha & 7.86 & 0.94 & 15.13 & 0.78 & 21.80 & 0.54 \\
Jukjeon & 48.78 & 0.84 & 85.90 & 0.63 & 114.86 & 0.37 \\
Jeomchon & 23.92 & 0.55 & 36.73 & 0.38 & 44.35 & 0.26 \\
Gajang & 5.10 & 0.67 & 7.87 & 0.45 & 9.54 & 0.35 \\
Yonggok & 5.54 & 0.99 & 10.69 & 0.99 & 15.48 & 0.98 \\
Seonsan & 9.84 & 0.96 & 18.31 & 0.87 & 25.57 & 0.75 \\
Seongseo & 43.14 & 0.98 & 80.87 & 0.93 & 114.02 & 0.86 \\
Gaejin & 44.32 & 0.86 & 71.70 & 0.63 & 89.47 & 0.42 \\
Jukgo & 43.71 & 0.95 & 78.76 & 0.85 & 107.39 & 0.73 \\
Jeongam & 74.14 & 0.96 & 137.95 & 0.86 & 193.20 & 0.74 \\
Miryang2 & 63.03 & 0.72 & 102.49 & 0.58 & 128.69 & 0.43 \\
Yangsan & 7.48 & 0.83 & 12.74 & 0.51 & 16.58 & 0.18 \\
\hline
\end{tabular}

performance of its tributaries. Table 1 shows the RMSE and EC from the flow forecasting results of $1 \mathrm{hr}, 2 \mathrm{hrs}$, and $3 \mathrm{hrs}$.

The hydrographs and simulation results present that the calibrated flow simulations are very close to the flow observation at all sites with relatively little error. All values of RMSE are 0 and values of EC are 1 . And the forecasting results exhibit that the model can successfully forecast the river flow with radar rainfall forecasts. The RMSE and EC values of all forecasts are considered as a satisfactory result. The accuracy of flow forecasts of Nakdong River is really great and exhibits the effect of this forecasting system. As expected, the accuracy of flow forecasts is gradually decreased in lead times extending from $1 \mathrm{hr}$ to $3 \mathrm{hrs}$. Some flow forecasts whose sites located at tributaries of Nakdong River are lower than their flow observation. The low estimation of river flow is likely caused by the low estimation of rainfall from radar rainfall forecasts.

\section{Conclusion}

The distributed hydrological watershed model with efficient calibration technology was successfully utilized in real-time simulation and forecast of multisite river flow in a large basin, Nakdong River Basin. We investigated the relationship between the water storage amount and basin discharge and demonstrated the approach of the multisite river flow realtime calibration method with the distributed hydrological model and forecast of river flow with radar rainfall forecasts data. The real-time calibration method offers a feasible and effective updating skill of state variables considering its spatial distribution pattern with the simulation result. The results indicate that calibrated flow simulations are very approximate to the flow observation at all sites and the accuracy of forecasting flow is gradually decreased with lead times extending from $1 \mathrm{hr}$ to $3 \mathrm{hrs}$. The research has clearly shown that the distributed hydrological model integration with realtime calibration technology is readily applicable for multisite real-time river flow analysis and forecasting in a large basin.

\section{Conflict of Interests}

The authors declare that there is no conflict of interests regarding the publication of this paper.

\section{References}

[1] H. A. P. Hapuarachchi, Q. J. Wang, and T. C. Pagano, "A review of advances in flash flood forecasting," Hydrological Processes, vol. 25, no. 18, pp. 2771-2784, 2011.

[2] L. S. Kuchment, "A two-dimensional rainfall-runoff model: identification of parameters and possible use for hydrological forecasts," in Proceedings of Hydrological Forecasting Symposium, pp. 215-219, Oxford, UK, 1980.

[3] G. Schultz, "Flood forecasting based on rainfall radar measurement and stochastic rainfall forecasting in the Federal Republic of Germany," in Weather Radar and Flood Forecasting, V. K. Collinge and C. Kirby, Eds., chapter 13, pp. 191-207, John Wiley \& Sons, Chichester, UK, 1987.

[4] B. E. Vieux and A. T. Jones, "Flood forecasting using WSR-88D rainfall estimates: distributed hydrologic simulation of two river basins in Oklahoma," in Proceedings of the 77th Annual Metting of the American Meteorological Society, pp. J83-J86, Long Beach, Calif, USA, February 1997.

[5] P. Y. Julien, B. Saghafian, and F. L. Ogden, "Raster-based hydrologic modeling of spatially-varied surface runoff," Water Resources Bulletin, vol. 31, no. 3, pp. 523-536, 1995.

[6] D. Shepard, "A two-dimensional interpolation function for irregularly-spaced data," in Proceedings of the ACM National Conference, pp. 517-524, 1968.

[7] A. H. Thiessen, "Precipitation averages for large areas," Monthly Weather Review, vol. 39, no. 7, pp. 1082-1084, 1911.

[8] D. M. Gray, Handbook on the Principles of Hydrology, National Research Council of Canada, Water Information Center, Water Research Building, Port Washington, NY, USA, 1970.

[9] P. S. Eagleson, "Climate, soil and vegetation, 2. the distribution of annual precipitation derived from observed storm sequence," Water Resources Research, vol. 14, no. 5, pp. 713-721, 1978.

[10] D. A. Woolhiser, R. E. Smith, H. O. Sharif, and D. C. Goodrich, KINEROS: A Kinematic Runoff and Erosion Model: Documentation and User Manual, ARS-77, U.S. Dept. of Agriculture, Agricultural Research Service, 1990.

[11] R. L. Bras, Hydrology: An Introduction to Hydrologic Science, Addison-Wesley, New York, NY, USA, 1990.

[12] W. H. Green and G. A. Ampt, "Studies of soil physics, part Ithe flow of air and water through soils," Journal of Agricultural Science, vol. 4, pp. 24-41, 1911.

[13] W. J. Rawls, D. L. Brakensiek, and N. Miller, "Green-Ampt infiltration parameters from soils data," Journal of Hydraulic Engineering-ASCE, vol. 109, no. 1, pp. 62-70, 1983. 
[14] K. Mahmood and V. Yevjevich, Unsteady Flow in Open Channels, Water Resources Publications, Fort Collins, Colo, USA, 1975.

[15] P. Y. Julien and B. Saghafian, "CASC2D user's manual: a twodimensional watershed rainfall-runoff model," Civil Engineering Report, Colorado State University, 1991.

[16] J. E. Nash and J. V. Sutcliffe, "River flow forecasting through conceptual models part I-a discussion of principles," Journal of Hydrology, vol. 10, no. 3, pp. 282-290, 1970. 


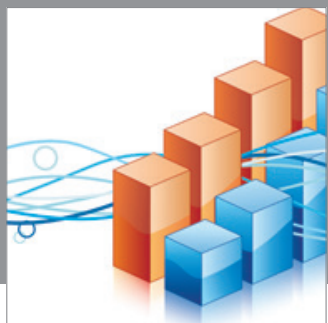

Advances in

Operations Research

mansans

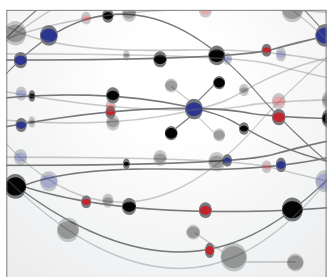

The Scientific World Journal
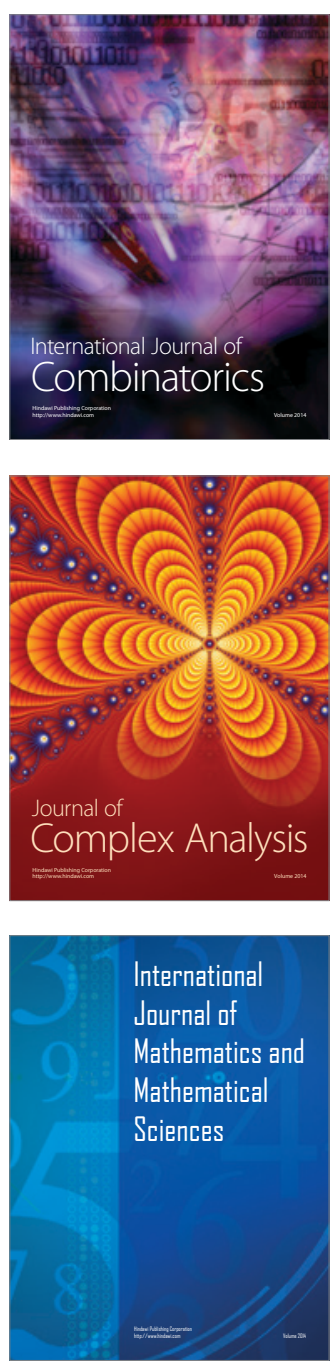
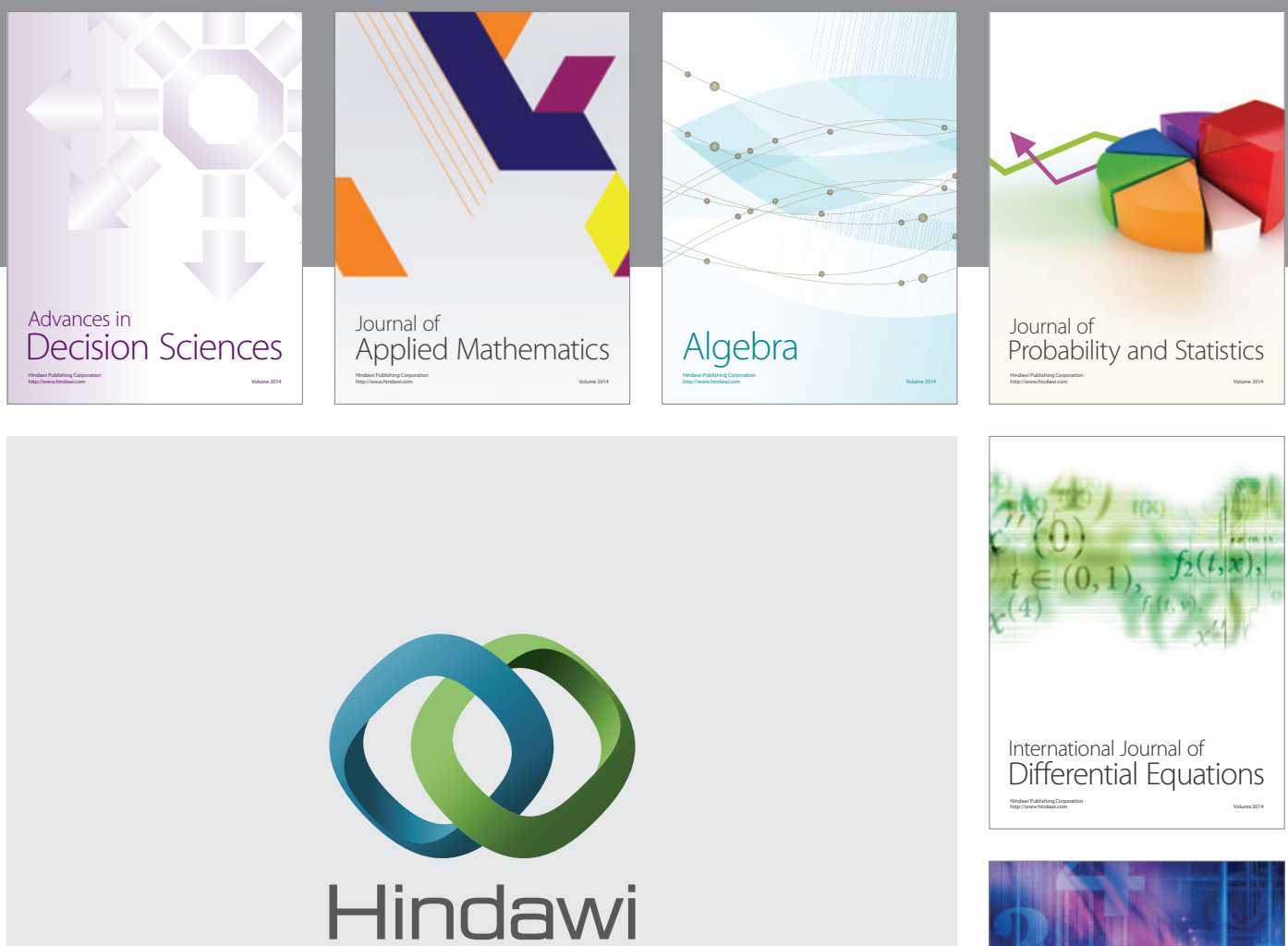

Submit your manuscripts at http://www.hindawi.com
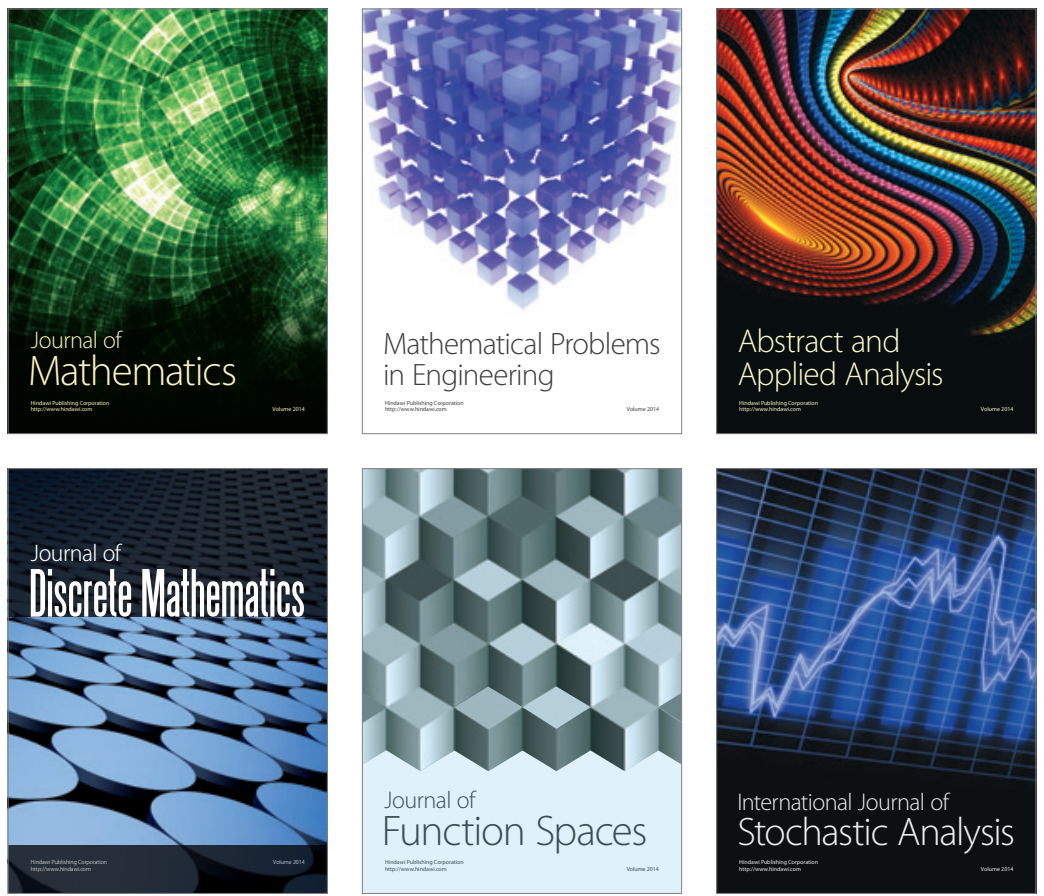

Journal of

Function Spaces

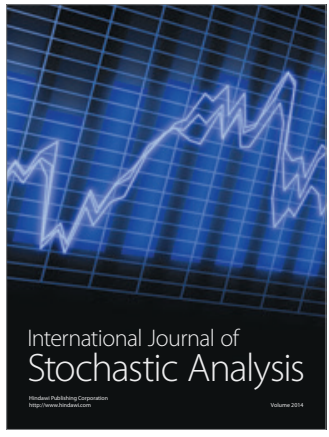

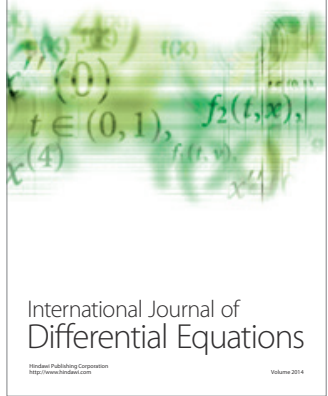
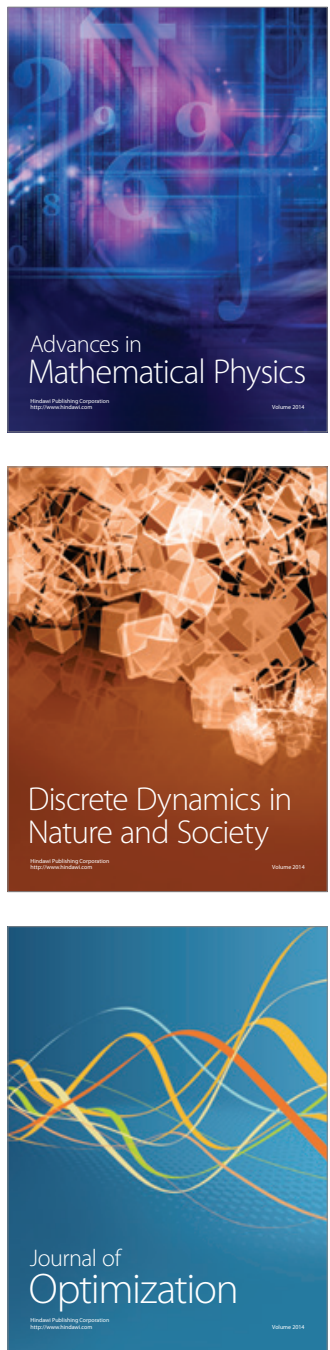